\title{
PI Controller based MPPT for a PV System
}

\author{
Govind Anil ${ }^{1}$, Nirmal Murugan ${ }^{2}$, Mufeed Ubaid $^{3}$ \\ ${ }^{1,2,3}$ School of Electrical and Electronics, VIT University, Vellore
}

\begin{abstract}
To meet the future energy requirement and to give quality and pollution free supply to growing and environment conscious population, the present world is giving special attention to natural, clean and renewable energy sources. Due to growing demand for electrical energy and environmental issues such as pollution and global warming effect, solar energy is considered among one of the best options for generating clean energy. In this paper a PI controller is used as an intelligent method for Maximum Power Point Tracking (MPPT) for a PV system. PI controller has been used for achieving the Maximum Power Point of a PV system. A boost converter is used to boost the voltage.
\end{abstract}

Keywords - PI controller, Maximum power point tracking, MPPT algorithm, Photovoltaic system

\section{INTRODUCTION}

Our world is witnessing a lot of energy crisis today and environment pollution is on a rising scale. In order to solve these problems emphasis is being placed on renewable sources of energy. Photovoltaic energy is of great importance in this regard as it is clean and inexhaustible and widely available. As the conventional energy sources are diminishing fast, the solar energy offers a very promising alternative, because it is free, abundant, pollution free and distributed throughout the earth .

The use of PV technology meets several challenges such as increasing the efficiency of PV conversion, ensuring the reliability of converters etc. Another drawback of PV system is that it does not provide a constant energy source because its output power changes with temperature and insolation level. To overcome these problems MPPT (Maximum Power Point Tracker) is used. In this project, an intelligent control technique using PI controller is associated to an MPPT controller in order to improve efficiency of the PV system.

\section{Photovoltaic Cell Model}

A model of a photovoltaic cell is shown in figure 1. From the circuit it can be seen that the current produced by the solar cell is equal to that produced by the current source, minus that which flows through the diode, minus that which flows through the shunt resistor .

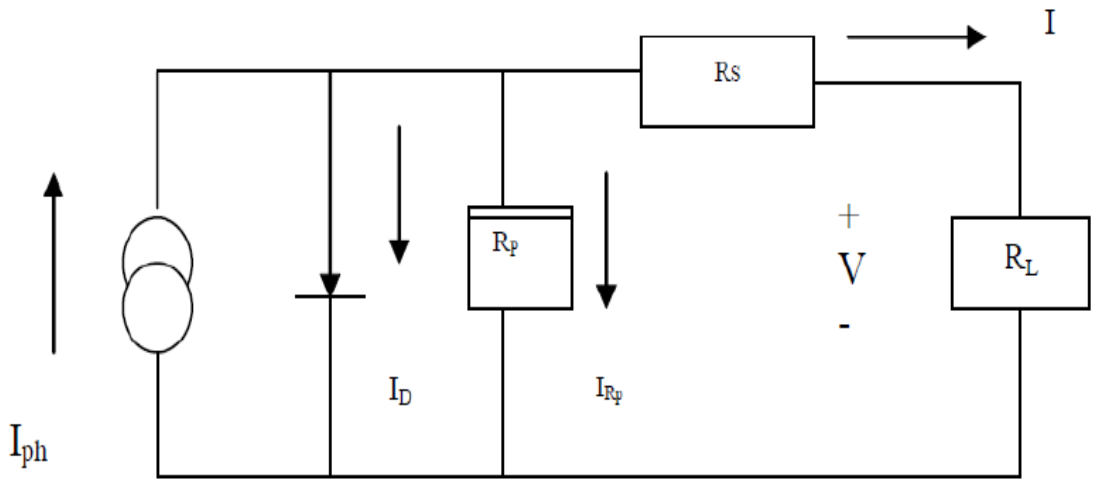

Fig. 1. PV cell circuit

Applying Kirchoff's law to the node where Iph, diode, Rp and Rs meet, we get

$\mathbf{I p h}=\mathbf{I D}+\mathbf{I R p}+\mathbf{I}$

We get the following equation for the photovoltaic current:

$\mathbf{I}=\mathbf{I p h}-\mathbf{I r p}-\mathbf{I D}$ 


$$
\mathrm{I}=\mathrm{I}_{\mathrm{ph}}-\mathrm{I}_{0} \cdot\left[\exp \left(\frac{V+I \cdot R_{S}}{V_{T}}\right)-1\right]-\left[\frac{V+I \cdot R_{S}}{R_{p}}\right]
$$

Where,

Iph is the Insolation current,

I is the Cell current,

$\mathbf{I}_{\mathbf{0}}$ is the Reverse saturation current,

$\mathbf{V}$ is the Cell voltage,

Rs is the Series resistance,

$\mathbf{R p}$ is the Parallel resistance,

$\mathbf{V}_{\mathbf{T}}$ is the Thermal voltage,

$\mathbf{K}$ is the Boltzman constant,

$\mathbf{T}$ is the Temperature in Kelvin,

$\mathbf{q}$ is the Charge of an electron.

The current to voltage characteristic of a solar array is non-linear, which makes it difficult to determine the MPP. The Figure below gives the characteristic I-V and P-V curve for fixed level of solar irradiation and temperature.

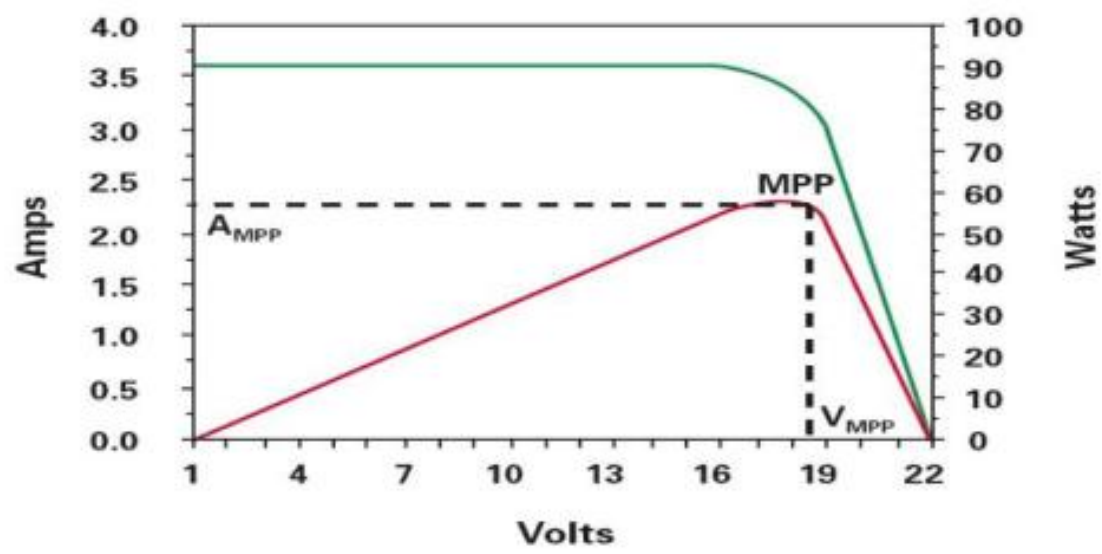

Fig.2. PV array characteristic curve

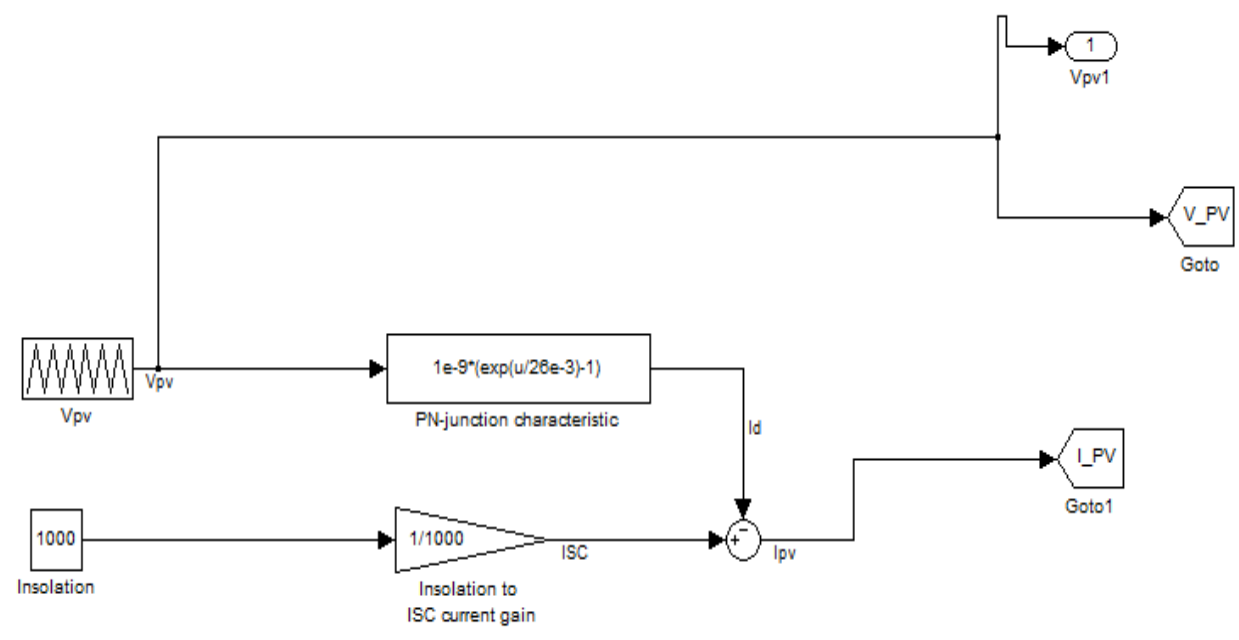

Fig. 3. Simulink model of solar panel 


\section{Mppt (Maximum Power Point Tracking)}

For any PV system, the output power can be increased by tracking the MPP (Maximum Power Point) of the PV module by using a controller connected to a dc- dc converter (usually boost converter). However, the MPP changes with insolation level and temperature due to the nonlinear characteristic of PV modules. Each type of PV module has its own specific characteristic. In general, there is a single point on the V-I or V-P curve, called the Maximum Power Point (MPP), at which the entire PV system operates with maximum efficiency and produces its maximum output power. This point can be located with the help of MPPT (Maximum Power Point Trackers) . PV system with MPPT controller has been shown in fig. 4.

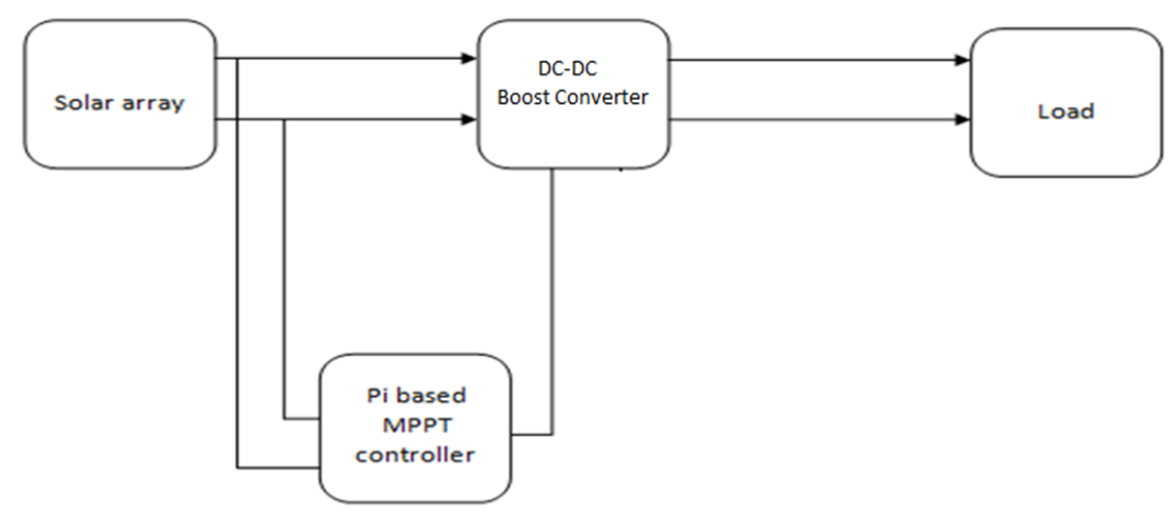

Fig. 4. PV system with MPPT

Maximum Power Point Tracker, frequently referred to as MPPT, is an electronic system that operates the PV modules in a manner that allows the modules to produce all the power they are capable of. MPPT is not a mechanical tracking system that "physically moves" the modules to make them point more directly at the sun. MPPT is a fully electronic system that varies the electrical operating point of the modules so that the modules are able to deliver maximum available power.

\section{Mppt Algorithms}

Many different algorithms have been proposed for tracking MPP in the past. Commonly used algorithms are Perturb and observe method, Incremental conductance method, Constant voltage method, Constant Current method etc. Perturb \& observe method is also known as P\&O method. In this method voltage or current of the PV array is modified to reach the MPP. For example the voltage is kept on increasing till the power increases. Constant voltage method is one of the simplest algorithms for MPPT. This method is based on the fact that the ratio of the array's maximum power voltage, VMPP, to its open-circuit voltage, Voc, is approximately constant. Constant current method is similar to constant voltage method .

\section{Simulation And Results}

Solar rays fall on the solar panel. This produces the reference current and reference voltage. These are the references used for maximum power point tracking. From the reference voltage, triangular pulses are generated. This is the input for the maximum power point tracker.

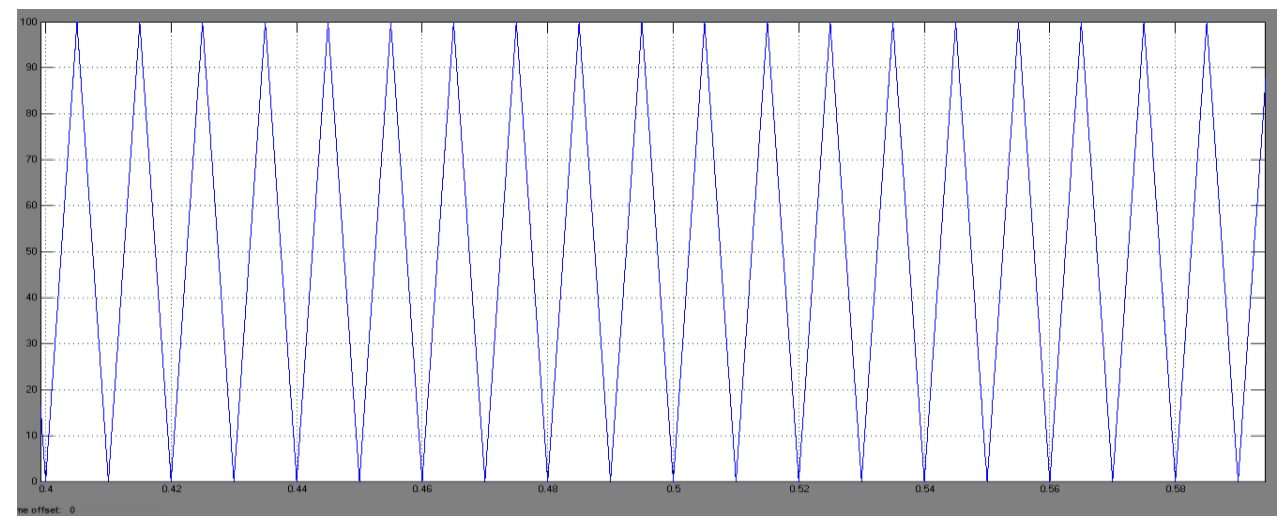

Fig.5. Triangular reference voltage with amplitude $=100 \mathrm{~V}$ 


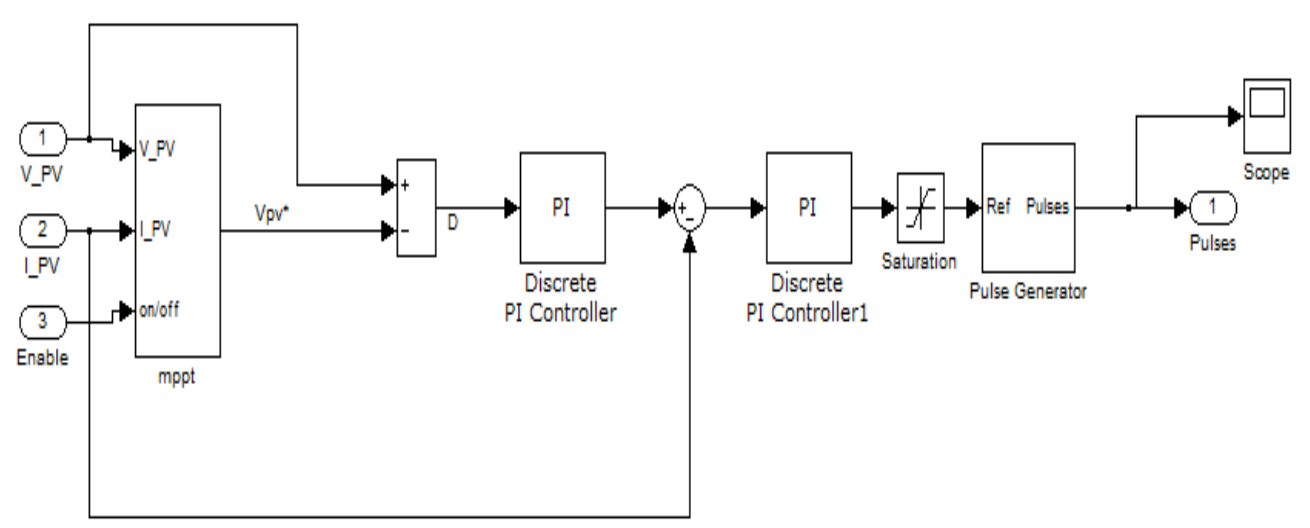

Fig. 6. MPPT connected to PI controller and pulse generator

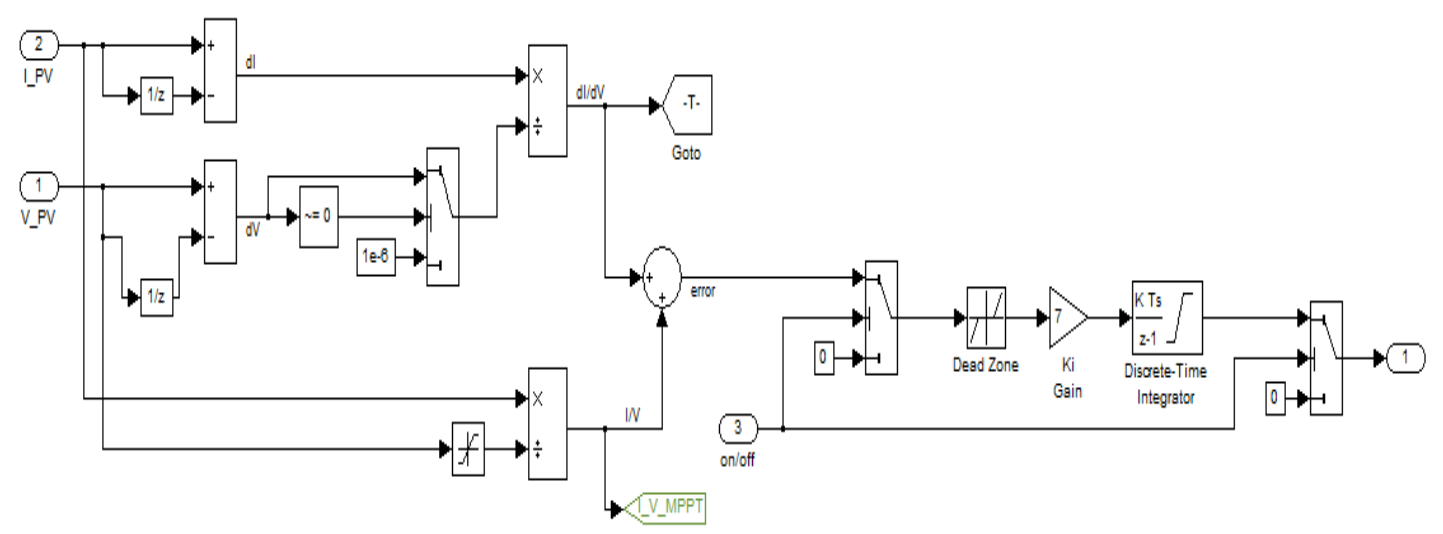

Fig.7. Simulink model of MPPT

The triangular pulses generated are then passed on to the maximum power point tracker where the maximum power point is tracked using a suitable algorithm and this value is compared with the reference voltage and current from the solar panel and fine-tuned using two PI controllers. This then generates reference pulse using a pulse generator which triggers the MOSFET and sets the boost circuit into action.

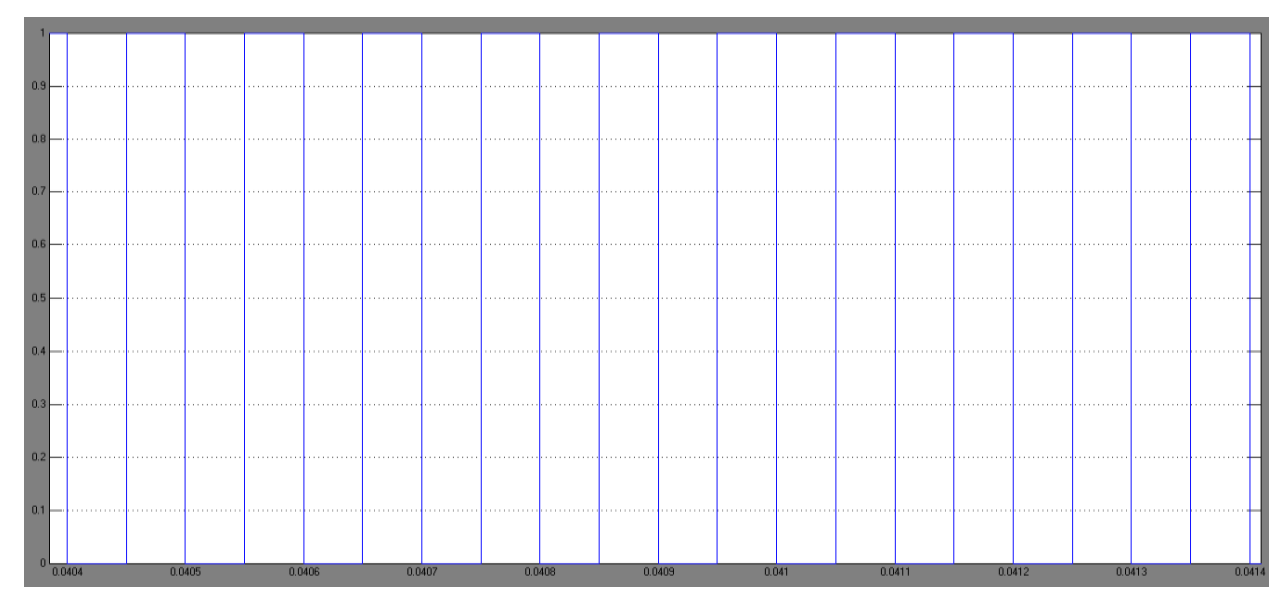

Fig: 5.5 Square pulse output from MPPT 


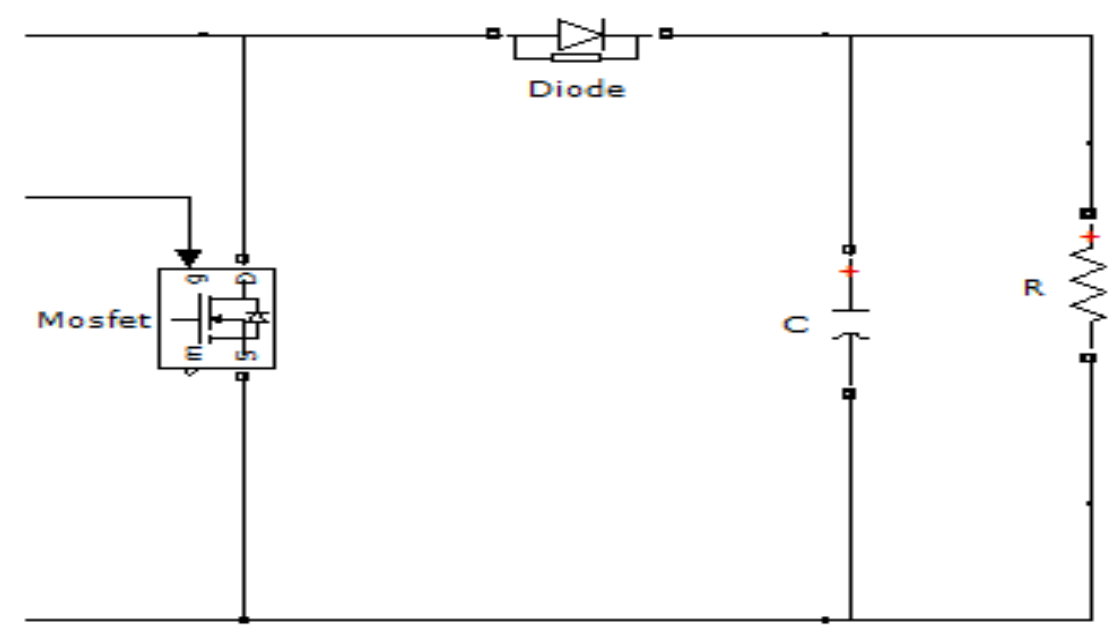

Fig.8. Simulink model of boost converter

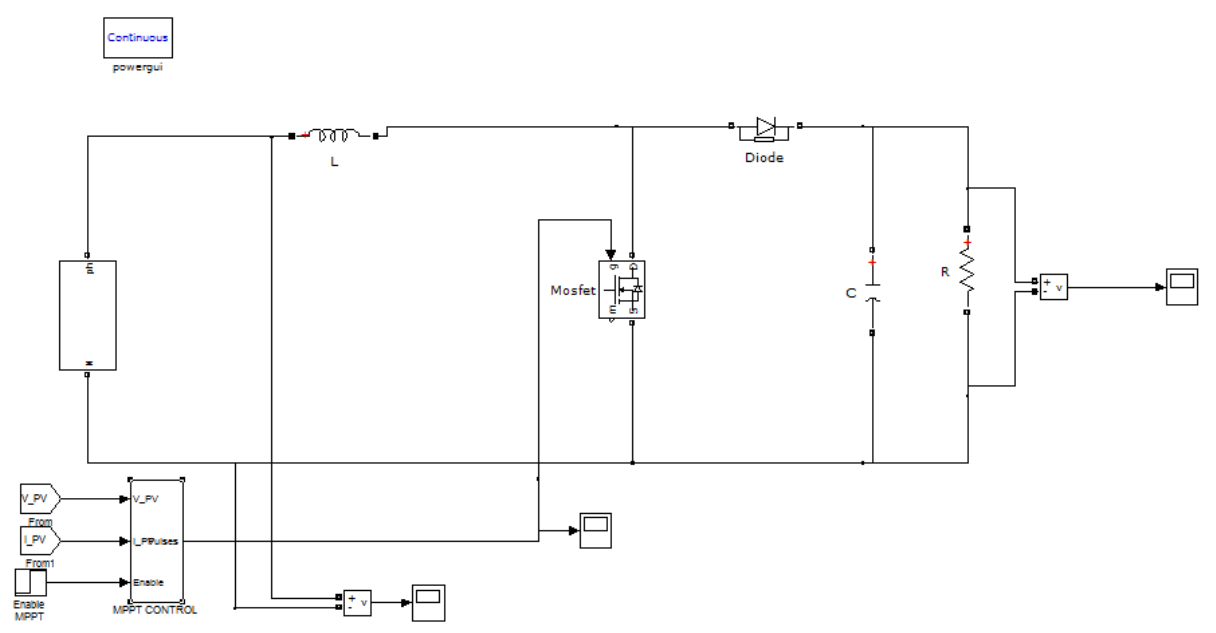

Fig.9. Simulink model of the system

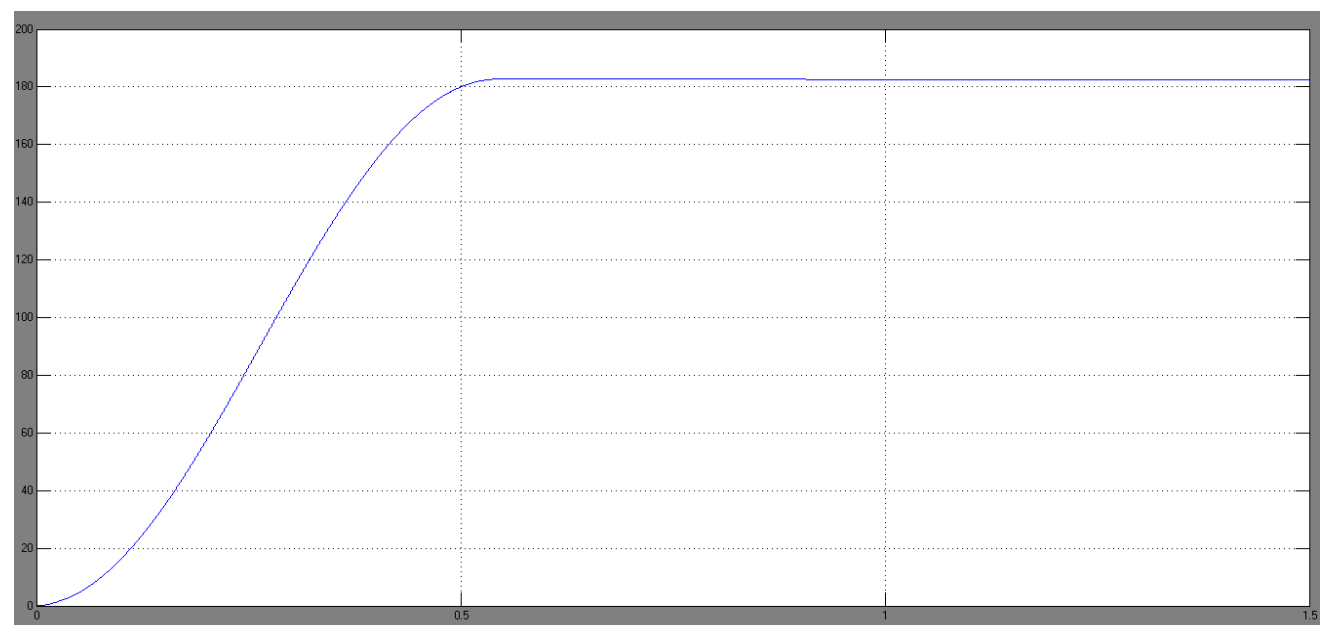

Fig.9. Output voltage after boosting 


\section{Conclusion}

A Photovoltaic system with an intelligent Maximum power point tracker (MPPT) has been modeled using MATLAB software. The algorithm used for MPPT controller is based on PI controller. The entire PV system is simulated and simulation results are verified. From the results we found out that the PV system becomes more efficient when a MPPT controller is included in the system when compared to a PV system without an MPPT controller. This technique using PI controller was able to reach the MPP quickly and oscillation is close to zero. The maximum power point tracker tracks the maximum power point (MPP) and the boost converter boosts the output voltage from the solar panel to the maximum power point voltage thus improving the efficiency of the panel.

\section{References}

[1]. Kimiyoshi Kobayashi, Hirofumi Matsuo and Yutaka Sekine, "A novel optimum operating point tracker of the solar cell power supply system" ,IEEE Conference on Power Electronics,Volume 3, 20-25 June 2004.

[2]. M. G. Villalva, J. R. Gazoli, and E. R. Filho "Comprehensive Approach to Modeling and Simulation of Photovoltaic Arrays" IEEE Trans. Power Electr., vol. 24.

[3]. Y.Kuo-"Maximum Power Point Tracking controller for photovoltaic energy conversion system"-IEEE Trans Ind. Electron-Volume 48-2001.

[4]. Nicola Femia, Giovanni Petrone, Giovanni Spagnuolo, Massimo Vitelli "Optimization of Perturb and Observe Maximum Power Point Tracking Method" IEEE transactions on power electronics, vol. 20, no. 4, July 2005.

[5]. D. P. Hohm and M. E. Ropp, "Comparative Study of Maximum Power Point Tracking Algorithms", Progress in photovoltaics: research and applications Prog. Photovolt: res. Appl. 2003.

[6]. Xuejun Liu and Luiz A. C. Lopes, “An Improved Perturbation and Observation Maximum Power Point Tracking Algorithm for PV Arrays", 2004 35th Annual IEEE Power Electronics Specialists Conference.

[7]. Chung-Yuen Won, Duk-Heon Kim, Sei-Chan Kim “A New Maximum Power Point Tracker of Photovoltaic Arrays Using Fuzzy Controller", IEEE transaction 1994.

[8]. S. Armstrong and W.G Hurley "Investigating the Effectiveness of Maximum Power Point Tracking for a Solar System", IEEE Conference on Power Electronics, 2005. 